\title{
Are Health Economics Making Us Sick?
}

$\mathbf{F}$

or those of us who have been involved with PET for the past 2 decades, it never ceases to amaze that this technology struggled for so long to gain acceptance by funding bodies and thereby assume a pivotal role in routine clinical practice. Despite our daily experience of its benefits and accumulation of a vast body of evidence indicating its diagnostic superiority over conventional imaging techniques that are currently funded for cancer evaluation, reimbursement for PET has been either restricted or denied in many countries.

At the forefront of this standoff between the clinical community and health care funding bodies are institutionalized health technology assessment (HTA) bodies, which not only have the ear of third-party payers but also are usually funded by them. HTA groups

\section{See page 1668}

have convinced funding bodies that there is insufficient high-quality evidence of clinical effectiveness and costeffectiveness to justify clinicians' assertions that ${ }^{18}$ F-FDG PET should be a routine clinical tool. The paper by Schreyögg et al. (1) in this issue of The Journal of Nuclear Medicine attempts to satisfy this supposed deficiency by evaluating the cost-effectiveness of ${ }^{18} \mathrm{~F}-\mathrm{FDG} \mathrm{PET} / \mathrm{CT}$ in non-small cell lung cancer in the context of the German health care system. Before providing commentary on this paper, we need

Received Jul. 9, 2010; revision accepted Aug. 5, 2010.

For correspondence or reprints contact: Rodney Hicks, Centre for Cancer Imaging, Peter MacCallum Cancer Centre, 12 St. Andrew's Place, East Melbourne, Victoria 3002, Australia. E-mail: Rod.Hicks@petermac.org

COPYRIGHT (C) 2010 by the Society of Nuclear Medicine, Inc.

DOI: 10.2967/jnumed.110.079772 to give some general background into the motivation for such studies.

In the debate regarding funding of PET, we can identify a fundamental disconnection in the perspectives of the clinical community and HTA groups and a power imbalance. Through the potent instrument of influencing reimbursement decisions, institutionalized HTA has been able to set both the methodologic and the temporal agenda for the introduction of new technologies. The International Network of Agencies for Health Technology Assessment (INAHTA), which has member agencies in North America, Europe, and Australia, has taken a special interest in PET. This agency provides a forum where health policy is discussed (2). Accordingly, decisions in one jurisdiction can influence those in another. In Australia, a 1999-2000 review of the PET literature by the Medicare Services Advisory Committee, an INAHTA member, concluded that there was insufficient evidence at that time from which to draw definitive conclusions about the clinical effectiveness and cost-effectiveness of PET. Although this decision did not reflect the true findings of the supporting scientific committee (3), it led to the Australian PET Data Collection Project (APDCP) to address what were perceived to be limitations in the evidence base supporting PET funding. The result was-for almost a decade - to restrict both the number of sites able to provide PET services and the number of indications for which funding was available.

With the stated aim of assessing evidence of impact on patient management, the Medicare Services Advisory Committee apparently dismissed seminal works demonstrating the impact and cost-effectiveness of whole-body PET in oncology $(4,5)$ and a substantial body of preliminary evidence on its management impact in the Australian context, available in 1999 and subsequently published in leading nuclear medicine and oncology journals (611). This dismissal has resulted in a recapitulation of studies in which there were already strong data supporting the clinical utility of PET. For example, an Australian study published in 2002 evaluated 102 consecutive patients with suspected recurrent colorectal cancer and reported that PET directly and appropriately influenced management in 59\% of patients (9). As part of the APDCP, Scott et al. essentially repeated this study (12) and documented management change in $65.6 \%$ of patients with suspected but unproven metastases and in $49.0 \%$ of patients being considered for metastasectomy, nicely bookending the result from the earlier study. Each of the published APDCP studies (13-16) already had a published counterpart in the Australian context (10,17-19).

In the current issue of The Journal of Nuclear Medicine, we see another example of a national funding body ignoring existing evidence. Over the past decade, HTA reviews in most countries have belatedly accepted evidence that ${ }^{18} \mathrm{~F}$-FDG PET is more accurate than conventional imaging in the staging of non-small cell lung cancer but have questioned the cost at which patient benefits are achieved. Despite evidence that hybrid PET/CT provides even greater diagnostic value (20) than PET alone, the German Federal Joint Committee has yet to decide on reimbursement for PET/CT, presumably considering extrapolation from existing data on the cost-effectiveness of stand-alone PET to be unreasonable.

From the perspective of public health care systems, the concerns of HTA groups are entirely justified. An explosion in therapeutic options has greatly increased public expenditure on cancer care, yet reductions in cancer mortality have been disap- 
pointing. However, most of the recent increase in health care spending relates to new therapies. Imaging contributes to only a small proportion of cancer spending. It has been estimated that only around 5-6 cents of every dollar spent on lung cancer arises from imaging (21). In this context, it is not economically rational to focus on only the direct costs of PET. In a prospective, randomized trial of patients being considered for surgery, ${ }^{18} \mathrm{~F}-\mathrm{FDG}$ PET reduced futile thoracotomies by $51 \%$ (22). Notwithstanding the issue of whether the ethical requirements of clinical equipoise were met in randomizing patients to a staging paradigm that is known to be less accurate, the data were recapitulated in a Canadian study that also showed a $50 \%$ reduction in futile surgery with more than twice as many patients correctly upstaged and almost half as many incorrectly understaged by PET/CT, compared with conventional staging (23). A further prospective study demonstrated that PET affected management in over $50 \%$ of cases being considered for chemoradiotherapy (8). Importantly, around $25 \%$ of patients had previously unrecognized distant metastases, preventing the morbidity associated with futile attempts at cure. Another 25\% had their radiation treatment fields altered, primarily to include probable disease sites that would otherwise not have been included in the treatment volume. Relapse due to inadequate treatment selection and planning will inevitably lead to the additional direct medical and societal costs due to lost productivity and premature death. Beyond these costs, there are important considerations for resource allocation. In many parts of the world, access to radiotherapy services is severely constrained and waits are long. Excluding patients for whom curative radiotherapy is futile reduces radiotherapy duration from 6 to $1 \mathrm{wk}$, allowing eligible patients to get their radiotherapy earlier. Similar arguments can be made about futile surgical procedures.

Although Schreyögg et al. (1) have clearly been guided by methodology stipulated by German funding author- ities, their evaluation technique lacks a societal perspective. Decisions on whether to provide a public funding subsidy for a new diagnostic method should be based on a cost-benefit analysis rather than the partial perspectives provided by cost-effectiveness or costutility measures. These measures can be considered partial in that they do not incorporate the disparate costs to society associated with the different management approaches. These types of analyses also fail to capture, for example, the economic consequences that a more efficient diagnostic paradigm may have in reducing patient visits to the hospital and consequent productivity of care givers who accompany the patient.

Further, cost-effectiveness analysis does not fully evaluate the consequences of better matching patients to appropriate treatment. Although Schreyögg et al. (1) attempt to estimate the economic benefits of avoiding unnecessary surgery, they ignore the economic benefits of freeing up resources as a result of better treatment selection or the potential advantages to nonsurgical patients, who are, in fact, the group most likely to be spared futile treatment as a result of occult metastases being detected by PET (24). The authors were clearly influenced by HTA groups that stipulate that only imaging data confirmed by histology are valid. The exclusion of a large proportion of the patients in whom the validity of diagnosis cannot, for practical and ethical reasons, be validated pathologically critically biases their analysis. This bias is regrettable given that clinical and imaging follow-up is a robust method to establish the truth of imaging.

Another potential inaccuracy in the methodology used to estimate the economic consequences of ${ }^{18} \mathrm{~F}-\mathrm{FDG}$ PET is the adoption of arbitrary values for quality-of-life reductions related to surgery. Not only is the imputed quality-adjusted life year approach a fairly crude way of measuring well-being, but also the values chosen by the authors seem likely to be inaccurate. Recent research (25) found that surgery was associated with a hospital mortality rate of $3 \%$ and that all patients had a substantial decrease in their overall quality of life up to 4 mo after lung resection. Compared with the no-recurrence group, a proportion of the recurrence group (in large measure, a group of patients for whom incremental PET findings would be expected to reduce futile surgery) had significantly worse health-related quality of life on all dimensions except emotional functioning between 4 mo and 2 y after surgery. Thus, to suggest that unnecessary surgery decreases quality of life by 0.15 life years seems likely to be an underestimate. Moreover, from a clinical perspective, performing potentially fatal surgery that actually leads to deterioration in performance is completely unethical if that surgery has no hope of cure. Here, again, the process of health economic evaluation fails to meet even the basic principles of modern clinical practice.

Around the world, a huge expenditure is committed on the basis of detailed economic analyses of cost versus benefit to society. Major road and public transport infrastructures are justified by a myriad of calculations relating to benefits that range from improving efficiency to reducing traffic accidents. Yet in the domain of health care, where billions of dollars are expended each year and the direct impact is felt in illnesses and deaths, it is standard practice to base public funding decisions on simplistic evaluations heavily weighted to comparisons of the payers' expenditure rather than the benefit to society as a whole. It is a travesty that patients' access to PET has been so severely retarded by applying evaluation methods that are so limited in their economic scope and yet purport to protect the public interest. Perhaps one day, reason will prevail.

When nothing seems to help, I go and look at a stone-cutter hammering away at his rock perhaps a hundred times without as much as a crack showing in it. Yet at the hundred and first blow it would split in two, and I know it was not that blow that did it, but all that had gone before together.

Jacob A. Riis, journalist and social reformer (1849-1914) 
Rodney J. Hicks

Peter MacCallum Cancer Centre

East Melbourne,

Victoria, Australia, and

University of Melbourne

Melbourne, Australia

\section{Jeff Borland}

University of Melbourne

Melbourne, Australia

\section{REFERENCES}

1. Schreyögg J, Weller J, Stargardt T, et al. Costeffectiveness of hybrid PET/CT for staging of non-small cell lung cancer. J Nucl Med. 2010;51: 1668-1675.

2. Adams EJ, Almazan C, Morland B, Bradbury I, King R, Rheinberger P. Joint project of the International Network of Agencies for Health Technology Assessment: Part 2-Managing the diffusion of positron emission tomography with health technology assessment. Int $J$ Technol Assess Health Care. 2006;22:149-154.

3. Parliament of Australia Senate Web Site. Additional comments by Senator Milne. Available ab: http:// www.aph.gov.au/Senate/committee/clac_ctte/pet/ report/d02.htm. Accessed September 8, 2010

4. Valk PE, Pounds TR, Tesar RD, Hopkins DM, Haseman MK. Cost-effectiveness of PET imaging in clinical oncology. Nucl Med Biol. 1996;23:737743.

5. Valk PE, Abella-Columna E, Haseman MK, et al. Whole-body PET imaging with $\left[{ }^{18} \mathrm{~F}\right]$ fluorodeoxyglucose in management of recurrent colorectal cancer. Arch Surg. 1999;134:503-511; discussion 511-513.

6. Hicks RJ, Kalff V, MacManus MP, et al. ${ }^{18} \mathrm{~F}-\mathrm{FDG}$ PET provides high-impact and powerful prognostic stratification in staging newly diagnosed non-small cell lung cancer. J Nucl Med. 2001;42:15961604.

7. Kalff V, Hicks RJ, MacManus MP, et al. Clinical impact of ${ }^{18} \mathrm{~F}$ fluorodeoxyglucose positron emission tomography in patients with non-small-cell lung cancer: a prospective study. J Clin Oncol. 2001;19: 111-118.

8. Mac Manus MP, Hicks RJ, Ball DL, et al. F-18 fluorodeoxyglucose positron emission tomography staging in radical radiotherapy candidates with nonsmall cell lung carcinoma: powerful correlation with survival and high impact on treatment. Cancer. 2001;92:886-895.

9. Kalff V, Hicks RJ, Ware RE, Hogg A, Binns D, McKenzie AF. The clinical impact of ${ }^{18} \mathrm{~F}-\mathrm{FDG}$ PET in patients with suspected or confirmed recurrence of colorectal cancer: a prospective study. J Nucl Med. 2002;43:492-499.

10. Wirth A, Seymour JF, Hicks RJ, et al. Fluorine-18 fluorodeoxyglucose positron emission tomography, gallium-67 scintigraphy, and conventional staging for Hodgkin's disease and non-Hodgkin's lymphoma. Am J Med. 2002;112:262-268.

11. Ware RE, Matthews JP, Hicks RJ, et al. Usefulness of fluorine-18 fluorodeoxyglucose positron emission tomography in patients with a residual structural abnormality after definitive treatment for squamou cell carcinoma of the head and neck. Head Neck. 2004;26:1008-1017.

12. Scott AM, Gunawardana DH, Kelley B, et al. PET changes management and improves prognostic stratification in patients with recurrent colorecta cancer: results of a multicenter prospective study. J Nucl Med. 2008;49:1451-1457.

13. Scott AM, Gunawardana DH, Bartholomeusz D, Ramshaw JE, Lin P. PET changes management and improves prognostic stratification in patient with head and neck cancer: results of a multicenter prospective study. J Nucl Med. 2008;49:1593-1600.

14. Chatterton BE, Ho Shon I, Baldey A, et al. Positron emission tomography changes management and prognostic stratification in patients with oesophageal cancer: results of a multicentre prospective study. Eur J Nucl Med Mol Imaging. 2009;36:354-361.

15. Fulham MJ, Carter J, Baldey A, Hicks RJ, Ramshaw JE, Gibson M. The impact of PET-CT in suspected recurrent ovarian cancer: a prospective multi-centre study as part of the Australian PET Data Collection Project. Gynecol Oncol. 2009;112. 462-468.

16. Scott AM, Gunawardana DH, Wong J, et al Positron emission tomography changes management, improves prognostic stratification and is superior to gallium scintigraphy in patients with low-grade lymphoma: results of a multicentre prospective study. Eur J Nucl Med Mol Imaging. 2009;36: 347-353.

17. Duong CP, Demitriou H, Weih L, et al. Significant clinical impact and prognostic stratification provided by FDG-PET in the staging of oesophageal cancer. Eur J Nucl Med Mol Imaging. 2006;33:759-769.

18. Simcock B, Neesham D, Quinn M, Drummond E, Milner A, Hicks RJ. The impact of PET/CT in the management of recurrent ovarian cancer. Gynecol Oncol. 2006;103:271-276.

19. Connell CA, Corry J, Milner AD, et al. Clinical impact of, and prognostic stratification by, F-18 FDG PET/CT in head and neck mucosal squamous cell carcinoma. Head Neck. 2007;29: 986-995.

20. Lardinois D, Weder W, Hany TF, et al. Staging of non-small-cell lung cancer with integrated positronemission tomography and computed tomography. $N$ Engl J Med. 2003;348:2500-2507.

21. Dinan MA, Curtis LH, Hammill BG, et al. Changes in the use and costs of diagnostic imaging among Medicare beneficiaries with cancer, 1999-2006. JAMA. 2010;303:1625-1631.

22. van Tinteren H, Hoekstra OS, Smit EF, et al. Effectiveness of positron emission tomography in the preoperative assessment of patients with suspected non-small-cell lung cancer: the PLUS multicentre randomised trial. Lancet. 2002;359: 1388-1393.

23. Maziak DE, Darling GE, Inculet RI, et al. Positron emission tomography in staging early lung cancer: a randomized trial. Ann Intern Med. 2009;151: 221-228, W-248.

24. MacManus MP, Hicks RJ, Matthews JP, et al. High rate of detection of unsuspected distant metastases by PET in apparent stage III nonsmall-cell lung cancer: implications for radical radiation therapy. Int J Radiat Oncol Biol Phys. 2001;50:287-293.

25. Kenny PM, King MT, Viney RC, et al. Quality of life and survival in the 2 years after surgery for non small-cell lung cancer. J Clin Oncol. 2008;26:233241. 